\title{
Asian American Women Face the Bamboo Ceiling in American High- Tech Workplaces-Based on a case study of Ellen Pao v. Kleiner Perkins Leyi Cao
}

\author{
Nanjing Foreign Language School, Nanjing, Jiangsu Province, 210000, China \\ angela@cas-harbour.org
}

Keywords: Asian American women, Bamboo ceiling, US high-tech workplaces, Intersectionality.

\begin{abstract}
In the 21st century, Asian American women, as a group, are considered to face certain barriers-the bamboo ceiling in US high-tech workplaces specifically. The existence of such barriers and the choice of action toward the barriers become what people concern most about. Based on these issues, this paper first analyzes data to reveal the overview of the current situation of Asian American women in American High-Tech workplaces and are shown from comparisons between different social groups. Moreover, the paper also discusses a specific case raised by an individual Asian American Women against her employer company. Based on further analysis of the case, which is combined with the concept of intersectionality, the paper suggests more considerations of intersectionality and encourages more actions of Asian American women fighting for equality.
\end{abstract}

\section{Introduction}

The glass ceiling faced by Asian Americans in current US workplaces is often recognized as the bamboo ceiling, referring to the practices that keep Asians from entering higher-paying, and more prominent jobs. By further considering Asian American women as a social group, intersectionality, in this paper, is employed to recognizing the intersection of race and gender in this issue. This paper analyzes the bamboo ceiling faced by Asian American women in American high tech workplaces, especially in Silicon Valley. Firstly, the author employs data which shows the barriers faced in the United States by Asian Americans as a whole. Secondly, more specific data is used to reveal the more severe conditions of Asian American women. At this point, the concept of intersectionality is raised, considering Asian American women both from their race and gender. Thirdly, a specific case of a Chinese-American women Ellen Pao who fights against the Bamboo ceiling in the Silicon Valley is analyzed. The reason why Ellen Pao lost the case, the weaknesses and her influence on other Asian American women are analyzed. Through the analysis of the case, the importance of considering intersectionality is stressed, and the author also expresses hope that Asian American women will eventually break the bamboo ceiling. Overall, this paper aims to raise awareness of Asian American women's situation in hi-tech workplaces and suggests possible improvements in the fight for the Asian American women's rights in the workplace.

\section{Statistic analysis}

According to the 2010 US census, the population of Asian Americans had reached 17.3 million by the year 2010, or 5.6\% of the total US population. It is estimated that Asian American population will continue to grow to 43.2 million by 2050. Asian Americans are never the minorities in the US workplace, yet they face heavy barriers which are often hidden by the overall data. As illustrated in the following figure 1, Asians were found to be $27.2 \%$ of the professional workforce, but only $13.9 \%$ of executives in the professional workforce at Google, Hewlett-Packard, Intel, LinkedIn, and Yahoo. Compared to Caucasian, who were found to be $62.2 \%$ of the professionals while $80.3 \%$ of the executives, Asian Americans are severely under-represented in the workplace. 


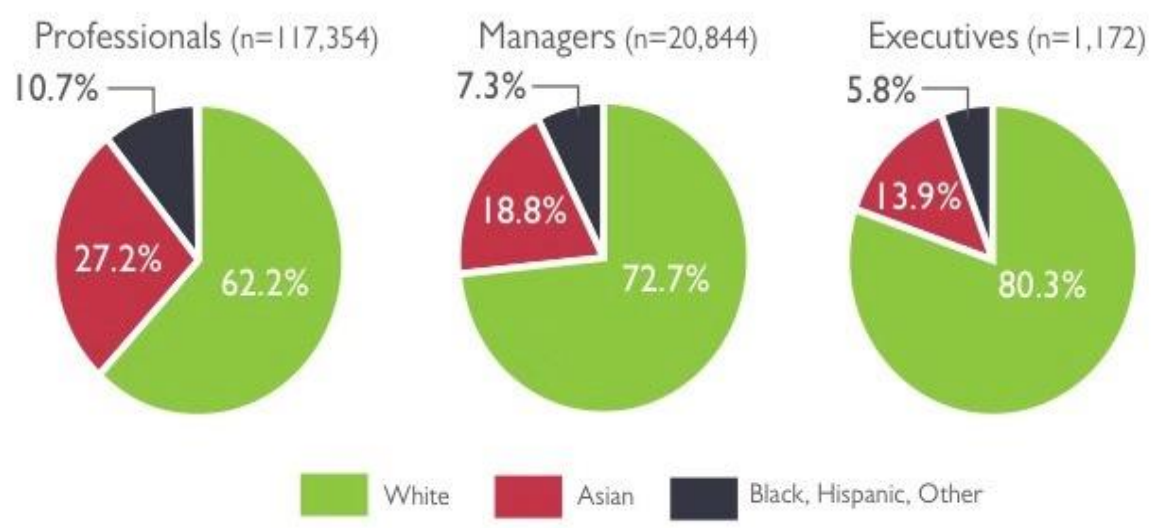

Fig. 1. Aggregate 2013 Management Pipeline by race[1]

(EEO-I data for Google, Hewlett-Packard, Intel, LinkedIn, and Yahoo)

Asian Americans overall face a bamboo ceiling in as they aspire for positions of managers and executives. However, simply viewing Asian American as one group ignores the more severe condition of Asian American women in the workplace.

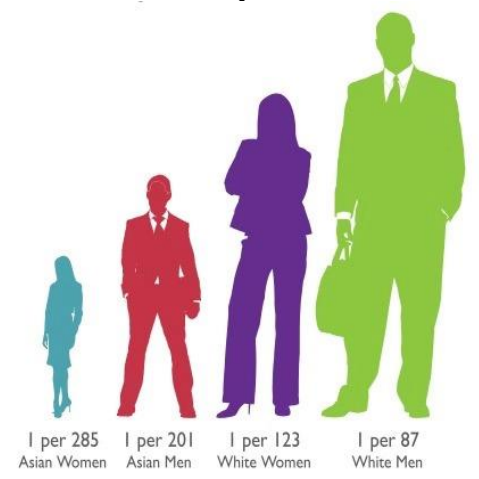

Fig. 2. Ratio of Executives for Asian/White Men and Women[1]

(EEO-I data for Google, Hewlett-Packard, Intel, LinkedIn, and Yahoo)

According to figure 2, there is only 1 Asian woman executive per every 285 Asian women in these companies, which is about $0.35 \%$. For Asian men, the executive ratio is 1 per 201 Asian men, which is about $0.50 \%$. White women were much more represented, with 1 executive per 123 white women, $0.81 \%$. White men, with 1 executive per $87,1.14 \%$, had the highest executive representation. When comparing Asian women with Asian men, Asian men were 143\% more represented than Asian women, implying that Asian women face more barriers to become executives than Asian men.

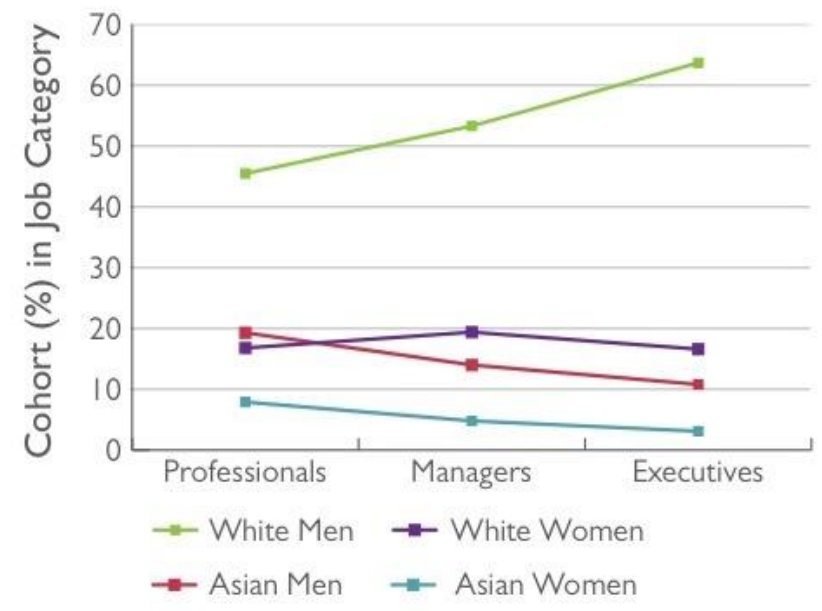

Fig. 3. 2013 Management Pipeline by race: White and Asian[1] (EEO-I data for Google, Hewlett-Packard, Intel, LinkedIn, and Yahoo) 


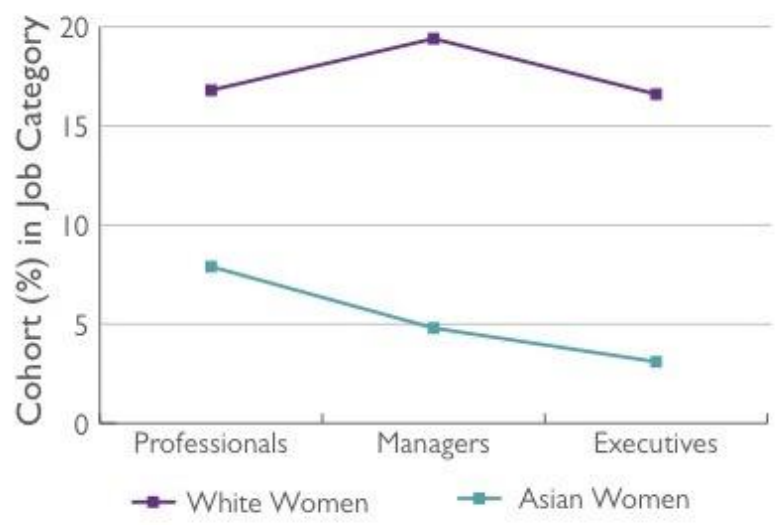

Fig. 4. 2013 Management Pipeline by race: White and Asian Women[1] (EEO-I data for Google, Hewlett-Packard, Intel, LinkedIn, and Yahoo)

Aside from the heavy barriers faced by Asian American women compared to the Asian American men, the data from figure 3 and 4 also reveals disadvantages for Asian women in comparison to the white women. In figure 3, the number of white women executives (16.6\%) nearly equals their professional representation (16.8\%), while the number of Asian women executives (3.1\%) is less than half of their professional representation (7.9\%). Moreover, as shown in figure 4, the number of White women shows an increase from professionals to executives, while the number of Asian women shows drastic decrease from professionals to executives. These figures all show the strong bamboo ceiling for Asian American women in executives compared to White women.

From the data above, it is clear that Asian American women experience more significant limitations than Asian American men or white American women. Therefore, it is misleading to consider Asian Americans as a whole without controlling for the drastically different stories of Asian Americans or women. Categorizing Asian American women in either groups will be ignoring specific difficulties they face because of their gender and race. Therefore, it is crucial to bring up the concept of intersectionality. Employed to Asian American women, intersectionality here means to take race and gender into account simultaneously, regarding Asian American women as a particular group of minority and facing issues of discrimination unique to this group. Though this concept may seem straight forward and self-evident, there are some people who doubt and criticize this theory. These critics worry and fear the reversing of society in which the white male is at the bottom of the pyramid. They also express concern that the employment of intersectionality will open the "Pandora's box", causing chaos when too many groups start to stand up and speak for themselves. For instance, in a 2018 clip for Prager University, an online platform for conservative educational videos, pundit Ben Shapiro described intersectionality as "a form of identity politics in which the value of your opinion depends on how many victim groups you belong to. At the bottom of the totem pole is the person everybody loves to hate: the straight white male." Despite these possible outcomes, ignoring the idea of intersectionality is, in fact, exacerbating the significant problem, especially discrimination faced by particular groups in the justice system. The following case of a Chinese American woman who sued her company for not promoting because of her gender will discuss the bamboo ceiling faced by Asian Americans in detail, showing the struggle of Asian American women to break the bamboo ceiling. To some extent, the result shows the problem of not taking intersectionality into account.

\section{A case study of Ellen Pao v. Kleiner Perkins}

The bamboo ceiling is a barrier faced by most Asian American women, but many of them fear to speak up, fitting into the stereotype of being quiet and hardworking. The case of Ellen Pao v. Kleiner Perkins, however, laid the groundwork for other women, showing how individuals can stand up for their own rights, and creating a direction for Asian American women with the same troubles in the workplace. 


\subsection{Overview of the case}

Ellen Pao v. Kleiner Perkins Caufield \& Byers LLC and DOES 1-20 is a lawsuit filed in 2012 in San Francisco County Superior Court by the plaintiff Ellen Pao for gender discrimination against her employer, Kleiner Perkins [3]. Pao is a Chinese-American woman from New Jersey who is very welleducated. She has a bachelor's degree in Electrical Engineering from Princeton University, a Juris Doctor from Harvard Law School and an MBA from Harvard Business School. The Plaintiff accused Kleiner Perkins Caufield \& Byers of not promoting her because of her gender and retaliating against her for complaining. Pao claimed that men were promoted ahead of women and that women's ideas were more likely to be dismissed compared to those from men. She also claimed that she started being excluded from important meetings after ending a sexual relationship with a partner Ajit Nazre. She stated that it was an unjust move for the corporation to fire her before the trial[4].

In response, the defendants emphasized how their firm had a large ratio of women employees compared to other venture capital firms. They presented statistics showing that the firm had a $20 \%$ female staff compared to the average of 7-11\% based on studies in 2011 and 2013. The defendants also argued that Pao was paid more than most of her male colleagues. Kleiner Perkins stated that limiting Pao's involvement was not a sign of discrimination. Moreover, they claimed that promotions to the senior partner position was by its very nature difficult and far from being automatic. They pointed out that 20 of the 25 people previously in Pao's position had also been passed over. They argued that Pao's firing was justified, presenting several negative performance reviews that she received and frequently described her as "entitled" and "not a team player". The defendants also brought the idea that Pao filed this law suit to help her husband, a hedge fund manager who filed for bankruptcy in 2012. However, Judge Harold Kahn ruled this defense out because it would employ over scrutiny on the Plaintiff's personal life. At the end of the trial, the jury were asked to vote over four claims:

1. Kleiner Perkins discriminated against Ellen Pao because of her gender.

2. Kleiner Perkins retaliated against her because of conversations in December 2011 and her memorandum in January 2012.

3. Kleiner Perkins failed to take all reasonable steps to prevent discrimination against her.

4. Kleiner Perkins retaliated by firing her after her conversations and memorandum.

A unanimous verdict was not required, only $75 \%$ of the jurors supported. There were no sexual harassment claims or the standard of proof which was preponderance of the evidence. The jury found 10-2 in favor of Kleiner Perkins on the first three claims, while on the fourth claim, the jury found 84 in favor of Kleiner Perkins which did not meet the threshold of 75\%. After 2 hours of deliberation, the court ruled in favor of Kleiner Perkins as one jury changed his vote from yes to no on the fourth claim[5]. Juror Marshallette Ramsey, who supported the plaintiff, said that it "seemed that the men, with the same character flaws that Ellen was cited with, were able to propel and continue[6]." Steve Sammut, on the other hand, was not convinced of what Pao experienced was gender discrimination, but he expressed a hope that Kleiner Perkins would still be punished for the way it treated employees in general[7].

\subsection{Reasons behind Ellen's losing}

Ellen Pao v. Kleiner Perkins Caufield \& Byers is seen as a landmark sexual discrimination lawsuit that shines a light on long-complained about ill-treatment of women especially Asian American women in Silicon Valley. Unfortunately, Ellen Pao lost the case. There are several reasons for this result:

1. Ellen Pao's evidence could not firmly demonstrate gender discrimination without persuasive source of data (e.g. the percentage of women promoted compared to men), which could easily be overthrown by the data of the percentage of women employees presented by Kleiner Perkins.

2. Ellen Pao failed to provide evidence that compares the promotion of women and men in the corporation which can be otherwise easily explained by the difficulty of promotion.

3. The sexual harassment claim was not raised because of the lack of evidence on both sides. 
4. The case may possibly include discrimination on Asian American women, which was not brought up and therefore not considered by the court.

According to reasons listed above, it is crucial to analyze the percentage of women in executives compared to men, instead of only focusing on the overall percentage of women in the workplace. Moreover, it is important to note that Asian American women, as a group, face both sexual and racial discrimination. Therefore, only considering one factor neglects the severity of the barriers (i.e. the bamboo ceiling) faced by Asian American women compared to other groups including Asian American men, white men and white women. It is suggested that courts take the issue of intersectionality[2] into consideration in specific cases because particular suffering of groups including Asian American women would be overlooked otherwise.

\subsection{Extended influence of the case}

Although Ellen Pao lost in this particular case, she started the trend of Asian American women fighting for their rights in the workplace as well as providing a way to solve such kind of problems. Moreover, she revealed potential drawbacks on the court, specifically not taking intersectionality in to account, and also indicated what can be improved in later attempts to sue companies for discrimination towards Asian American women, for instance, the need to provide specific evidence on the percentage of women and men being promoted. Other women (mostly Asian American women) who have had similar experiences as Pao stated that they are enlightened by Pao's case, realizing the need of fighting for their own rights at the workplace. Elizabeth Ames, the Senior Vice President of Marketing at Anita Borg Institute said "When the trial was going on, it was kind of a surreal experience because I personally felt like I could relate to all of the things that happened to her." Rachel Renock, the CEO of Wethos said "She really stuck her neck out. She opened the door for other women to do the same." Ellen Pao aroused the feeling of other Asian American women with the similar feeling and pushed them to take their experience seriously and encouraged them to stand up and fight for their own rights.

However, some are concerned that Ellen Pao's case would discourage companies employing women, especially Asian American women, because they do not want such case happen and ruin their reputation. To some degree, this might be true. But avoiding discrimination in the workplace never solves any problem. It simply creates a harmonious illusion that equality is reached in the workplace, yet in fact that is far from reality. Under such circumstances, discrimination in the workplace would either remain the current way, or even deteriorate, because people are not aware of this issue. Therefore, in order to eliminate discrimination in the workplace, Asian American women and other groups facing discrimination should start speaking out now, and the public should take their words much more seriously. There will be hope with relentless efforts.

\section{Discussion}

Actions have been taken by Asian American women initiated by the case discussed in the paper, but their influence was little. Legal cases similar to Ellen's were unsuccessful partially because of the failing to consider intersectionality[2], whereas simply taking it as a gender issue or a racial issue fails to reveal its real significance. Therefore, it can be reasonably inferred that the concept of intersectionality is crucial to seeking proper solutions. Meanwhile, more efforts need to be made from Asian American women, in order to raise more awareness of the bamboo ceiling among the public.

\section{Conclusion}

Based on statistics and case studies, Asian American women do face a serious bamboo ceiling in American high tech workplaces. Currently, more Asian American women start to become aware of the barriers they face in workplaces and stand up to speak for themselves. Though eliminating discrimination towards Asian American women in the workplace is very difficult, a positive attitude is needed to make changes towards the right direction. Future advocates of breaking the bamboo ceiling should learn from former cases like Ellen Pao v. Kleiner Perkins and make improvements of 
their evidence provided in the court. It is also crucial for the court to take the concept of intersectionality into consideration in order to fully understand the severe condition of specific groups like Asian American women. Though Asian American women's fight for breaking the bamboo ceiling in American high tech workplaces is long and hard, the situation will be improved with more awareness and efforts.

\section{References}

[1] B. Gee, D. Peck, J. Wong HIDDEN IN PLAIN SIGHT: Asian American Leaders in Silicon Valley, The Ascend Foundation, 2015.

[2] K. Crenshaw Demarginalizing the intersection of race and sex: a black feminist critique of antidiscrimination doctrine, feminist theory and antiracist politics In: University of Chicago legal forum, Los Angeles, pp.139-169, 1989.

[3] R. Burnson, Ellen Pao testifies in Silicon Valley gender-bias trial, 2015.[Online] Available:https://www.theglobeandmail.com/technology/ellen-pao-testifies-in-silicon-valleygender-bias-trial/article23374197/ [Accessed on Oct.8, 2019]

[4] E. Wiese, Man Ellen Pao accused of retaliation had bonus docked, 2015 [Online] Available:https://www.usatoday.com/story/tech/2015/03/02/ellen-pao-kleiner-perkins-tedschlein-cocky/24267571/ [Accessed on Oct.8, 2019]

[5] G. Liz and B. Nellie, Live: Ellen Pao Loses on All Claims in Historic Gender Discrimination Lawsuit Against Kleiner Perkins, 2015 [Online] Available: https://web.archive.org/web/20150327235113/https://recode.net/2015/03/27/live-the-pao-vkleiner-perkins-verdict/ [Accessed on Oct.18, 2019]

[6] A. Tsotsis, Two Jurors On Opposite Sides Share Their Pao Vs. Kleiner Perspectives 2015 [Online] Available:https://techcrunch.com/2015/03/27/two-jurors-on-opposite-sides-share-their-pao-vskleiner-perspectives/ [Accessed on Oct.18, 2019]

[7] G. Liz and B. Nellie, A Juror Speaks About His Vote for Kleiner Perkins but Still Wants the Firm to 'Be Punished, 2015 [Online] Available:http://www.recode.net/2015/03/30/a-juror-speaksabout-his-vote-for-kleiner-perkins-but-still-wants-the-firm-to-be-punished/ [Accessed on Oct.18, 2019] 